\title{
Artelogie
}

Recherche sur les arts, le patrimoine et la littérature de l'Amérique latine

17 | 2021

Transformaciones en Cuba contemporánea: cultura y sociedad

\section{Aproximaciones epidérmicas al contexto caribeño: una poética de lo epidérmico en «Maleficio», de Marta María Pérez Bravo}

\section{Cecilia González Godino}

\section{OpenEdition}

\section{Journals}

Edición electrónica

URL: https://journals.openedition.org/artelogie/10163

DOI: 10.4000/artelogie.10163

ISSN: 2115-6395

Editor

Association ESCAL

Referencia electrónica

Cecilia González Godino, «Aproximaciones epidérmicas al contexto caribeño: una poética de lo epidérmico en «Maleficio», de Marta María Pérez Bravo», Artelogie [En línea], 17| 2021, Publicado el 27 septiembre 2021, consultado el 15 septiembre 2022. URL: http://journals.openedition.org/artelogie/ 10163 ; DOI: https://doi.org/10.4000/artelogie.10163

Este documento fue generado automáticamente el 15 septiembre 2022

All rights reserved 


\title{
Aproximaciones epidérmicas al contexto caribeño: una poética de lo epidérmico en «Maleficio», de Marta María Pérez Bravo
}

\author{
Cecilia González Godino
}

1 La piel, como órgano responsable de la función de relación del ser humano, se encarga de establecer un vínculo entre el sujeto y su entorno. Y este vínculo es, cuando menos, bidireccional, esencial y sistemático. Así pues, cualquier alteración en la construcción de este, por mínima que sea, desencadena una serie de respuestas conscientes o inconscientes que desequilibran la conexión establecida entre la realidad interior y exterior del sujeto. Ya desde esta sencilla introducción podemos considerar la piel como una membrana mediadora entre la realidad externa e interna del sujeto, entre su realidad física y física. $\mathrm{Y}$, sin embargo, el órgano epidérmico no se limita a «mediar» entre el adentro y el afuera, sino que integra tanto funciones de protección y conservación como funciones de desarrollo e incluso de resistencia (Anzieu, 2016). Esta naturaleza paradójica de la piel, que la sitúa tanto en el plano orgánico como simbólico, se debe a su condición periférica, fronteriza: lo epidérmico, es decir, el carácter elemental de la piel como sistema, no surge del adentro o del afuera, de lo incluido o lo no incluido, sino del límite en sí mismo. Su origen y su naturaleza fundamental habitan (en) el margen, son esencialmente periféricos.

2 Enseguida vemos, entonces, que la piel trasciende su carácter puramente biológico, orgánico, para posicionarse como un marco simbólico de relación. Pues, de acuerdo con las formulaciones sobre la piel por Didier Anzieu, la piel es, para el sujeto, el espacio liminal donde los extremos no solo se encuentran y se relacionan, sino que adquieren un sentido como conjunto (Anzieu, 2016). Se trata de un espacio inabarcable e incognoscible, simultáneamente físico y psíquico, fluido y estático a la vez, de un espacio eternamente en progreso; cuando tratamos de definirlo - de encapsularlo en 
un significado-, queda inmovilizado y, por tanto, renuncia con la definición a su condición epidérmica.

3 Este mismo fenómeno que hemos atribuido a la piel sucede, según lo formulado por Édouard Glissant en Poética de la Relación (1997), con la materia en evolución que conforma y compone el universo, y solo es posible acceder a esta naturaleza en desorden, a esta serie dinámica de accidentes, a través de la noción de Caos, una postulación científica que formula la lógica fractal de las turbulencias universales: un sistema de fenómenos y accidentes dinámicos del entorno que se repiten a nivel global sin lógica aparente, así como formas de remediación de los elementos que lo conforman (resistencia, re-presentación, re-definición, re-organización, re-petición...). De la noción de Caos se desprende la de chaos-monde, acuñada por Édouard Glissant para referirse al contacto caótico pero inexorable de las formas de cultura y de los modos de relación humanos (1997).

4 Asimismo, biológica y simbólicamente, la piel funciona como un espacio transtemporal dentro de Caos y, como tal, retiene la experiencia transgeneracional del chaos-monde entendiendo esta «experiencia» como una totalidad infinita de pliegues, de accidentes, de estímulos, de turbulencias y de los residuos que, como veremos más adelante, deja este proceso de pliegue, como la violencia- (Glissant, 1997). Piel y Caos comparten esta naturaleza constitutiva biológica y simbólica; sin embargo, lo epidérmico no solo proyecta las turbulencias de Caos, sino que encarna este contacto, esta Relación tomando prestada la noción de Glissant- en sus expresiones conscientes e inconscientes, físicas y psíquicas, internas y externas, este contacto. En este contexto, lo epidérmico correspondería a uno de los modos de (acceso a la) Relación, es decir, a una de las máquinas articuladoras de los procesos de Relación y de sus combinaciones, pues se corresponde con y encarna «lo dinámico, lo relacional, lo caótico; cualquier elemento fluido y variado $\mathrm{y}$, además, incierto (esto es, inaprehensible), pero fundamental en cada instancia y muy probablemente lleno de instancias de invariabilidad» ${ }^{1}$ (Glissant, 1997: 137). 


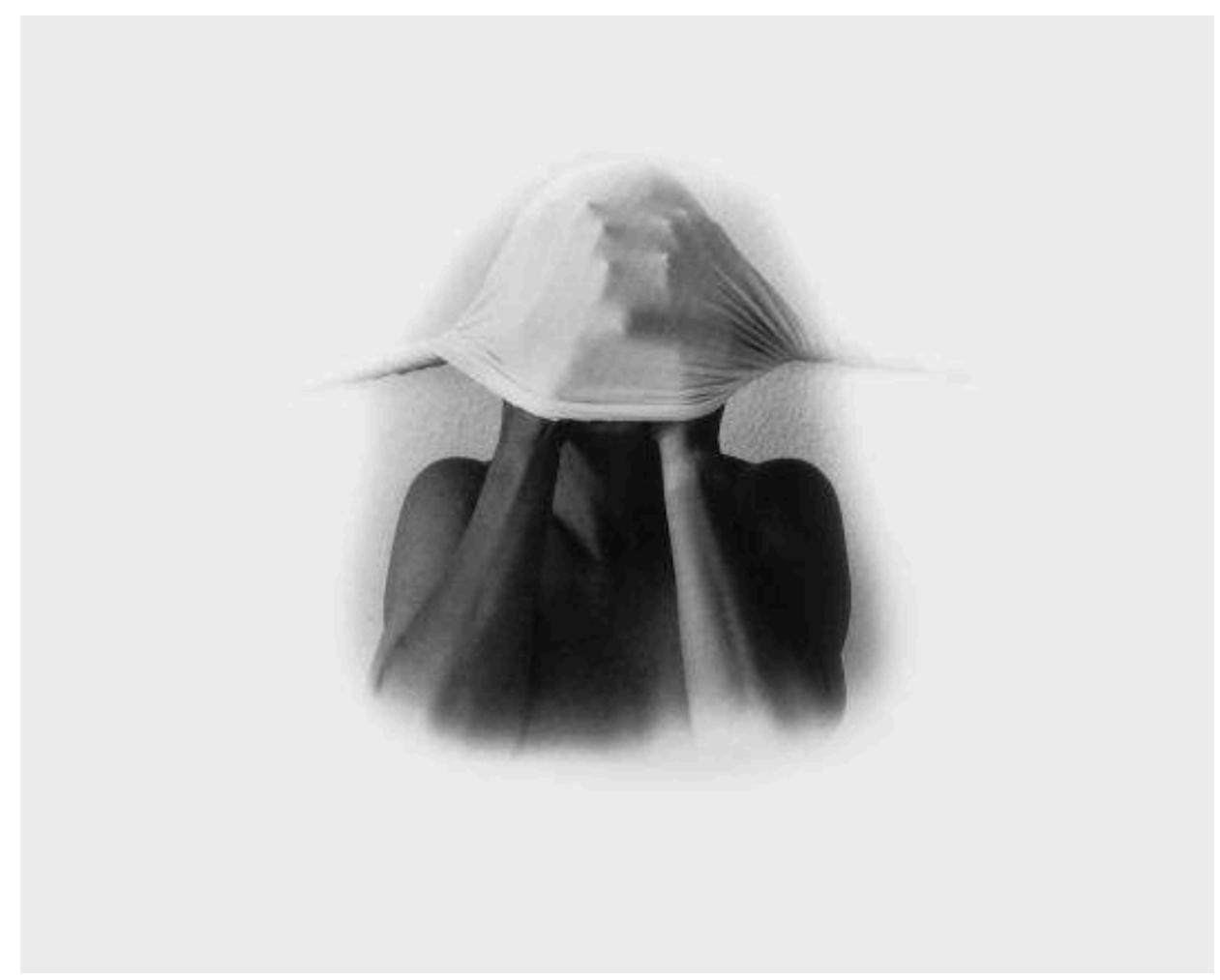

Figura 1. «Maleficio», Marta María Pérez Bravo (1992)

Dicho esto, el objetivo de este artículo es articular la forma en que una aproximación epidérmica contribuye al análisis de productos culturales caribeños y, más específicamente, al proyecto artístico de la fotógrafa y artista de performance cubana Marta María Pérez Bravo (La Habana, 1959), así como proponer dicha aproximación epidérmica como instrumento de análisis privilegiado, como filtro fractal, para atisbar los objetivos de Caos en la realidad archipelágica y los productos culturales del Caribe. En este sentido, la obra de Marta María Pérez Bravo queda encuadrada en un arte fotográfico cubano surgido en la década de los noventa -comúnmente denominado «fotografía del Período Especial»- que reemplazó las narrativas revolucionarias épicas y heroicas por un interés en el sujeto (cubano y caribeño) (Hernández Tapia, 2015). Y este esfuerzo fotográfico constituyó en sí mismo un acto contrahegemónico, una «vuelta al sujeto», a lo primitivo y a lo orgánico, como la piel o los fluidos corporales, como instrumentos de reconocimiento de memoria y de subjetividades culturales. En este sentido, el proyecto artístico fotográfico de Pérez Bravo, que se extiende desde la década de 1980 hasta la actualidad -y de donde extraemos la obra «Maleficio» (Fig. 1), presentada por primera vez en 1992-, articula este movimiento decolonial apostando por una fotografía profundamente performática, des-pigmentada y des-enfocada. «Maleficio» es una de tantas islas celulares y monocromáticas que conforman en relación simbiótica y casi atemporal este proyecto archipelágico $^{2}$, una de tantas reconfiguraciones y fragmentos que parecen conjurar una totalidad «otra» del contexto caribeño.

6 Ahora bien, ¿de qué forma se relaciona lo epidérmico con lo caribeño?, ¿qué elementos son extrapolables de una a otra realidad? y ¿cuál sería la contribución de lo epidérmico al análisis de productos culturales caribeños? Para empezar, ambas realidades comparten una geografía simbólica: la naturaleza archipelágica del Caribe es 
transferible a la naturaleza fragmentada y relacional de la piel. Ambas constituyen realidades fractales y archipelágicas que repiten y (re)producen el des-orden y la discontinuidad de su conjunto ${ }^{3}$. Y estas instancias de transferencia son encarnadas por la artista en su performance. En La isla que se repite, Antonio Benítez Rojo vincula los modos de relación de Caos al archipiélago caribeño, por lo que sí cabría plantearse una aproximación al vínculo Caos-Caribe desde la geografía simbólica descrita, esto es, desde una geografía epidérmica: el archipiélago como topografía orgánica «en cierta manera $»^{4}$ a la deriva donde fragmentación y unificación convergen de la misma manera que las células en la piel, sobre una base heterogénea y heterónoma (nunca autónoma), pero siempre relacional y relacionada (Flores y Stephens, 2017). Establecer una analogía explícita entre piel y archipiélago como grupos simbólicos permite aproximarse a los «inciertos viajes de significación» (Benítez Rojo, 1989: 16) caribeños desde una nueva perspectiva epistemológica que integra rizomáticamente lo de-seleccionado, lo marginal, lo liminal.

7 Ambas realidades -lo epidérmico y lo archipelágico- habitan en lo inasible, lo inaprehensible, y Marta María Pérez Bravo materializa esta paradoja: los límites de lo epidérmico-archipelágico no son discernibles, como no lo son los de su obra; evade la inteligibilidad colonial (o absoluta) sin enfrentarse a ella, reclamando su derecho a la opacidad; y sus formas de resistencia a esta inteligibilidad se despliegan desde el límite, del mismo modo en que la sábana blanca se desenreda al entrar en contacto con el sujeto en «Maleficio». Ni la artista ni la lógica epidérmico-archipelágica persiguen una legitimidad hegemónica, sino que operan en el plano de lo inaprehensible, creando formas de agencia «otras», formas opacas de existencia y de persistencia cuya turbulencia percibimos bajo la sábana. Asimismo, tanto el carácter epidérmico como el archipelágico recurren a estrategias de reapropiación de sus espacios simbólicos por medio de una poética, eludiendo o excediendo así el esfuerzo recodificador, limitador y territorializador (pos)colonial. Aunque se establezcan estructuras de control tanto sobre la tierra como sobre el cuerpo -y la carne-, la naturaleza archipelágica antillana y epidérmica no es susceptible de ser controlada, legislada o contenida bajo la sábana despigmentada y blanqueada de lo absoluto.

8 Así como no es posible identificar límites temporales o espaciales en la piel, tampoco puede establecerse su centro o su origen ni es posible «centralizarla». Una aproximación epidérmica implica poner en marcha un proceso de des-centralización, observar la realidad a través de su filtro fractal para tratar de re-presentarla y de redefinirla. Y, en el caso caribeño, esta des-centralización no es negociable: cuando la otredad es fundacional, cuando el margen constituye el espacio originario (y original), un análisis centralizado no puede ser productivo, precisamente porque las estrategias territorializadoras no pueden desplazar lo que nace en una posición desplazada, desde lo desplazado y el pliegue. En consecuencia, a ambos conjuntos se les puede aplicar carácter no solo de archipiélago, sino de meta-archipiélago, entendido por Antonio Benítez Rojo como una realidad rizomática, ilimitada y descentralizada. El mero hecho de reconocer o de apelar desde lo poético a esta naturaleza meta-archipelágica -un exceso o rebosamiento de raíces, límites y centros- invoca una "supuración» que supone de por sí un acto de resistencia, un acto de reapropiación de la agencia caribeña, un acto de re-conocimiento de una agencia «otra». Ante todo, la cultura antillana es performática — «de ejecución de un ritual» (Benítez Rojo, 1989: 26)—, por lo que la identificación de formas de agencia «otras» permite atisbar su totalidad y acercarse a descifrar las implicaciones de sus dinámicas sincréticas y diaspóricas. Y lo 
epidérmico sutura ambos movimientos - el contacto del sincretismo y la expansión de la diáspora-con procesos históricos de acumulación y de trasplantación.

9 Aunque Marta María Pérez Bravo recurre a la fotografía como su formato de preferencia, invoca estas formas «otras» inaprehensibles y descentralizadas de agencia desde lo ritual, la entrada más antigua a la totalidad de Caos y otra realidad cuya experiencia esencial está en el proceso, no en la consecución. Lo ritual constituye uno de los muchos códigos performativos de lo epidérmico y posiciona la carne como el lugar orgánico donde estos procesos se (re)producen y donde el sujeto busca una inteligibilidad contrahegemónica, como plataforma orgánica para la expresión y retención física de memoria transgeneracional. Los mecanismos de poder y de resistencia que colisionan en el proceso de sujeción se producen y se almacenan en el espacio-piel, pero se muestran, son (re)presentados y exteriorizados en o a través del lugarcarne. En «Maleficio», la artista ofrece su cuerpo, su carne, como lugar-altar que apela a un orden «otro» desde la ritualización performativa de su agencia. Y de esta agencia «otra» emerge un conocimiento «otro».

Este conocimiento -de ahora en adelante, conocimiento «epidérmico»- es esencialmente performativo y ritualístico, puesto que invoca el contacto turbulento entre espacio y lugar, piel y carne, lieu y milieu de mémoire, y lo significa dentro del chaos-monde. Una aproximación epidérmica revela cómo la cultura antillana trata de conjurar su violencia social fundacional como estrategia de reapropiación, como un gesto de persistencia. En palabras de Benítez Rojo: «La cultura de los Pueblos del Mar [pueblos antillanos] expresa el deseo de conjurar la violencia social remitiéndose a un espacio que sólo puede ser intuido a través de lo poético, puesto que siempre presenta una zona de caos» (1989: 33). Y aunque cualquier conjuración o significación de lo epidérmico es efímera en esencia, como lo es un acto de performance -pues el mismo hecho de definir lo fosiliza en una realidad estática-, funciona como catalizador de violencia social, como una aproximación «otra» o relectura que incluye exceso, margen $\mathrm{y}$, en última instancia, supuración. La performance de la artista funciona como «catarsis carnavalesca» y canaliza esta violencia fundacional caribeña invocando la piel como espacio periférico de representación (Benítez Rojo, 1989: 39).

11 Dado que el conocimiento epidérmico tiene como base las formas de contacto entre culturas o chaos-monde, también implica en parte un conocimiento discursivo (esto es, una aproximación racial, étnica, de género...) que se hace perceptible desde la carnelugar hacia la piel-espacio. Sin embargo, la naturaleza rizomática de la piel -o "propioceptiva», en su terminología biológica- implica en sí misma una opacidad, una continuidad asimétrica de contactos o pliegues y de residuos o líneas de fuga ${ }^{5}$. Esto permite pensar el conocimiento epidérmico como una suerte de máquina feed-back de memoria cuyos procesos de contacto y relación son esencialmente asimétricos, simultáneamente de flujo y de interrupción, cuyo «mecanismo poético no puede ser diagramado en las dimensiones convencionales, y [cuyas] instrucciones se encuentran dispersas en estado de plasma dentro del caos de su propia red de códigos y subcódigos» (Benítez Rojo, 1989: 34). Así pues, las dinámicas (pos)coloniales impresas en las geografías y los cuerpos antillanos, como penetración, trasplantación, territorialización y extractivismo, no son unidireccionales ni se encuentran exclusivamente enraizadas en el binomio isla-continente/centro-periferia. El conocimiento epidérmico -mediante instrumentos poéticos- permite acceder a lo caribeño como realidad periférica constitutiva; sí, es en la existencia de la periferia que 
lo hegemónico, lo absoluto se completa, pero este mismo postulado presupone su fracaso como unidad de significación. El recurso de Pérez Bravo a la fragmentación corporal -que constituye su proyecto artístico como un meta-archipiélago en sí mismo (ver Fig. 2) - no solo revela la tensión que surge de la lógica hegemónica del in/out, sino que destapa la dependencia constitutiva de ambas realidades: aunque «Maleficio» solo reproduce un fragmento, reclama la existencia opaca de cuerpo, piel, carne y sábana que excede la imagen y que, sin habitarlo como tal, conforma lo absoluto desde su otredad. El sujeto no solo se produce hacia dentro, hacia lo hegemónico, sino que se produce simultáneamente en el margen, que tanto en la fotografía de Pérez Bravo como en las topografías terrestres y corporales caribeñas constituye una realidad difuminada, liminal. Esta continuidad en la opacidad, que recuerda a la erosión de los límites físicos de una isla por el mar, apunta también a que cada sujeto no constituye sino un fragmento de una piel colectiva, una isla en un archipiélago epidérmico, conectada de forma asimétrica y relacional.
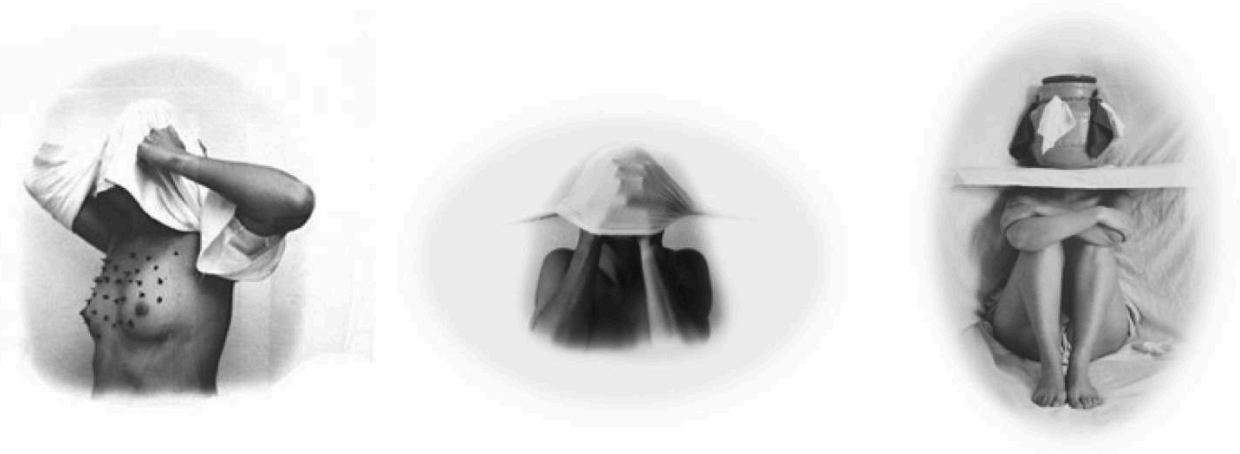

Figura 2. De izquierda a derecha, «Protección» (1990), «Maleficio» (1992) y «Más fuertes nos protegen mejor» (1995). Ejemplos del proyecto artístico de Marta María Pérez Bravo

Antes postulamos la piel como espacio periférico de (re)presentación para el contexto caribeño, de lo que se desprende que las identidades caribeñas - por su condición igualmente periférica- se constituyen dentro y desde este espacio. Tomando como referencia las tesis de Stuart Hall sobre la identidad (2011), se presupone un «Ser» [Être] que se constituye en el proceso, en el «Siendo» [Étant], una identidad que escapa de la territorialización y se aferra no a sus orígenes, sino a su naturaleza relacional, a su condición de nodo en el des-orden del chaos-monde. Aunque esta noción de identidad no es exclusiva del contexto caribeño, sí es aplicable y reconocible en su conjunto: como identidades «otras»-silenciadas, antihegemónicas-, las identidades caribeñas son constitutivas de las identidades (llamémoslas) «unas», esto es, identidades que han adquirido una ilusión de «unidad» a partir de lo que no son, de lo que excluyen, forzando así un proceso de "cierre» basado en dinámicas de sobredeterminación y naturalización (Hall, 2011: 5) ${ }^{6}$. Como constitutivas de lo «uno», las identidades liminales $\mathrm{u}$ «otras» -tampoco exclusivas del Caribe- dejan al descubierto la artificialidad de este cierre forzado por el discurso hegemónico y se constituyen desde o a partir del cierre, rebosando y resistiendo sus límites «blanqueadores» ${ }^{7}$. En este sentido, la artista encarna en «Maleficio» este proceso de sujeción «otra»: la constricción del límite hegemónico, materializada en el blanqueamiento y la homogeneidad artificial de la sábana, y el exceso o la supuración que se desprende de este cierre forzado en el recurso a la fragmentación y al difuminado. 
13 del resto de las Antillas, la herida original del margen queda marcada por procesos de trasplantación forzosa y la inmediatez geográfica y temporal del contacto entre culturas, es decir, por la turbulenta acumulación de experiencia y expresiones transversales del chaos-monde, que para Glissant conlleva una respuesta igualmente expansiva: violencia (1997: 141). El sujeto condenado a este «maleficio» se debate entre dos movimientos esencialmente humanos, de diferenciación y de legitimación, que desencadenan procesos inestables de liberación, especificación y significación, y desvelan el trauma del presente inmemorial, poniendo en tensión la piel como espacio de memoria con la carne como lugar donde se acumula de forma transgeneracional y transtemporal la violencia social de esta memoria. Las identidades liminales no se completan, como su contraparte, mediante un punto de encuentro o de sutura entre los discursos y las prácticas hegemónicas (Hall: 6), sino que se mantienen asimétricamente fracturadas, fragmentadas, condenadas a este «maleficio» insular y periférico. Mientras que podemos pensar en otros escenarios - no liminales- donde las expresiones de memoria y trauma se encuentran más sedimentadas, la experiencia caribeña - por su naturaleza esencialmente cercana a Caos y por su carácter meta-archipelágico- es de fluidez marítima, es decir, se encuentra inmersa en ciclos de oleaje que se superponen, que se acumulan, que se suceden inexorablemente, sin dejar que la espuma, el residuo, sea absorbido por la arena. En palabras de Antonio Benítez Rojo, el Caribe padece de «una circularidad impuesta por el aislamiento y, sobre todo, por la repetición implacable de las dinámicas económico-sociales propias del sistema de plantación» (1989: 223). Y esta acumulación, porosa, supurante, ahistórica -epidérmica, por excelencia- no solo queda proyectada en las identidades caribeñas, sino que tatúa con estos procesos de acumulación inmemorial su piel simbólica. (Re)conocer esta supuración - «supuración, siempre supuración» (Benítez Rojo, 1989: 19)— implica reconocer una herida originaria provocada por el desgarro y el desarraigo, por la otredad fundacional antillana, por la génesis desde el margen. Y esta herida abierta se encuentra en un permanente proceso de cicatrización, se mantiene abierta por la inmediatez y la continuidad turbulenta de sus contactos con Caos, por sus ciclos de oleaje (Hall, 2011: 3) ${ }^{8}$.

En definitiva, a través de una aproximación epidérmica y, más concretamente, mediante la formulación del espacio-piel y el lugar-carne como máquina feed-back de memoria, como instrumento asimétrico de (re)conocimiento de la herida originaria causada por la otredad, es posible (re)conocer formas «otras» de agencia y de resistencia que invocan la violencia y el desarraigo originales de identidades liminales como las caribeñas. Este proceso de (re)conocimiento se sirve de instrumentos de lo poético (que en el contexto caribeño son esencialmente performativos, rituales) para desencadenar una sutura "otra», no constrictora ni oclusiva, que media entre la naturaleza liminal caribeña y los discursos y prácticas hegemónicos. Como causa y efecto de lo hegemónico, simultáneamente de su prevalencia y de su fracaso, las identidades caribeñas no pueden ser analizadas desde una experiencia de des-pliegue o de re-pliegue; se trata, más bien, de un proceso continuo de «pliegue», constituido a partir de la opacidad, la turbulencia, el contacto y la acumulación caótica, inmediata y desordenada de ritmos, lenguas, razas, orígenes, religiones... Las performances estáticas de Marta María Pérez-Bravo, como «Maleficio», funcionan como catalizadores de este chaos-monde y encarnan diferentes implicaciones de los contactos inmediatos $\mathrm{y}$ turbulentos que colisionan en el sujeto cubano-caribeño. 
aproximación epidérmica al Caribe y a sus productos culturales liminales es una de tantas aproximaciones al contexto y a las identidades caribeñas para procurar establecer un sistema relacional que incluya «su fragmentación, su inestabilidad, su recíproco aislamiento, su desarraigo, su complejidad cultural, su dispersa historiografía, su contingencia y su provisionalidad» (Benítez Rojo, 1989: 27). Lo epidérmico revela estos procesos de (re)conocimiento: un conocimiento «otro» performativo, fluido, periférico, archipelágico. Se trata pues de un (re)conocimiento de la Relación, pues presupone un des-centramiento y un des-plazamiento, al tiempo que plantea la proyección epistemológica y estética de la naturaleza biológica y simbólica de la piel, esto es, una poética de lo epidérmico.

\section{BIBLIOGRAFÍA}

ALBÁN ACHINTE, Adolfo (2013), «Pedagogías de la re-existencia: artistas indígenas y afrocolombianos», en WALSH, Catherine E., Pedagogías decoloniales: prácticas insurgentes de resistir, (re)existir y (re)vivir, 443-468. Ediciones Abya-Yala, Quito.

ANZIEU, Didier (2016). El yo-piel. Biblioteca Nueva, Madrid.

BENÍTEZ ROJO, Antonio (1989), La isla que se repite. Ediciones del Norte, Hanover.

DELEUZE, Gilles (2012), Diferencia y repetición. Paidós, Madrid.

DELEUZE, Gilles y GUATTARI, Félix (1994), «Introducción: Rizoma», Mil mesetas. Pre-Textos, Madrid.

FLORES, Tatiana, y STEPHENS, Michelle Ann (2017), «Toward an Archipelagic Model of Insular Caribbean Art», en Relational Undercurrents: Contemporary Art of the Caribbean Archipelago, pp. 14-27, Duke University Press, Durham.

GLISSANT, Édouard (1992), Caribbean Discourse. University Press of Virginia, Charlottesville. GLISSANT, Édouard (1997), Poetics of Relation. The University of Michigan, Ann Arbor.

HALL, Stuart (2011), «Who needs identity», en HALL, Stuart y DU GAY, Paul, Questions of Cultural Identity. SAGE Publications, Nueva York.

HERNÁNDEZ TAPIA, Lidia (2015), «La vuelta al sujeto en la fotografía cubana del fin de milenio: Marta María Pérez Bravo y René Peña», en LL Journal, City University of New York (CUNY), Nueva York.

MARTÍN-SEVILLANO, Ana Belén (2011), «Crisscrossing Gender, Ethnicity, and Race: African Religious Legacy in Cuban Contemporary Women's Art», en Cuban Studies, pp. 136-154, University of Pittsburgh Press, Pittsburgh.

TAYLOR, Diana (2003), The Archive and the Repertoire. Duke University Press, Durham. 


\section{NOTAS FINALES}

1. Traducción propia. Texto original: "This "orientation" then leads to following through whatever is dynamic, the relational, the chaotic-anything fluid and various and moreover uncertain (that is, ungraspable) yet fundamental in every instance and quite likely full of instances of invariance» (Glissant, 1997: 137).

2. El proyecto fotográfico de Marta María Pérez Bravo se asemeja en sí mismo a un archipiélago, no solo por la asincronía de las obras que lo componen, sino porque el recorrido de cada una de sus obras es errático, singular y simbiótico. Sin ir más lejos, la obra analizada, «Maleficio», aparece fechada en diferentes años dependiendo de la fuente, y lo mismo parece ocurrir con el resto de fotografías. Algunas se encuentran agrupadas en series dentro de un proyecto común, pero no siempre son expuestas como conjunto; otras siguen su propio camino, pero no cabe duda de que este des-orden, esta turbulenta y caótica referenciación, atraviesa el proyecto creativo de la autora.

Algunas de las galerías y espacios donde se han expuesto estas obras son: Museo de Arte de Pori (Finlandia), Galerie El Patio (Bremen, Alemania), Trockmorton Fine Art (Nueva York), Espacio Aglutinador (La Habana, Cuba), Centro de la Imagen (México DF), Museo del Barrio (Nueva York), ARCO (Madrid, España), Galería Fadireh Cadot (París, Francia). Puede encontrarse una lista completa de sus exposiciones, así como de premios y reconocimientos, en la web de la autora: https://martamariaperezbravo.com/bio/.

3. Salvo menciones específicas al archipiélago como realidad física, se toma la noción de «archipiélago» o «archipelágico» como realidad simbólica, esto es, fragmentada, periférica, inestable y a la deriva...

4. En La isla que se repite, Antonio Benítez Rojo caracteriza la realidad cubana como una realidad «en cierta manera», es decir, turbulenta, inestable por naturaleza, incognoscible y no susceptible de ser definida (1989: 18-19).

5. Estas nociones de «pliegue» y de «línea de fuga», que provienen de la teoría rizomática de Deleuze y Guattari, se corresponden en lo epidérmico a las expresiones rizomáticas del carácter propioceptivo de la piel, es decir, a las formas asimétricas en que la naturaleza rizomática interna de esta máquina logra transmitir la totalidad incognoscible del conjunto, en este caso, el Caribe.

6. Texto original: «The unity, the internal homogeneity, which the term identity treats as foundational is not a natural, but a constructed form of closure, every identity naming as its necessary, even if silenced and unspoken other, that which it 'lacks'» (Hall, 2011: 5)

7. El término «blanqueamiento» aplicado a este contexto proviene, como indica Adolfo Albán Achinte (2013) de Frantz Fanon: «El cuadro que configuró la colonialidad (Quijano, 2001) en sus diversas manifestaciones, del poder, del saber y del ser, fue pintado con una paleta de colores en donde la diversidad cromática se convirtió en un problema, había que pintarlo todo de blanco o por lo menos matizarlo a toda costa, en la epidermis y en las mentalidades. Fanon (1974) precisó que esto era un proceso de blanqueamiento, es decir, la despigmentación de la piel y de la conciencia para asimilarse a la supremacía de lo aséptico, puro, luminoso e inmaculado: lo blanco. La cromática en este sentido, coadyuvó a la racialización, la negación y la exclusión [...]» (Albán Achinte, 2013: 444) [Los resaltados son propios].

8. Texto original: «[Identity] operates across difference, it entails discursive work, the binding and marking of symbolic boundaries, the production of 'frontier-effects'. It requires what is left outside, its constitutive outside, to consolidate the process» (Hall, 2011:3). 


\section{RESÚMENES}

El arte y los estudios de performance, entre otros movimientos contemporáneos, no solo han posicionado el cuerpo como una cartografía simbólica, sino que también han puesto de relieve la naturaleza paradójica de la piel, su condición de realidad periférica, a caballo entre lo físico y lo psíquico, lo orgánico y lo inorgánico. Y es precisamente a través de esta liminalidad que una aproximación epidérmica permite establecer espacios «otros» de transferencia, de representación y de agencia en el contexto archipelágico caribeño. La piel como espacio periférico de re-conocimiento fuerza un descentramiento, una dislocación, una disyunción que permiten atisbar en productos culturales surgidos de contextos liminales una totalidad «otra»simbiótica, turbulenta, fractal- que elude y rebosa, por medio de mecanismos poéticos, los esfuerzos recodificadores y territorializadores (pos)coloniales. En este sentido, Marta María Pérez Bravo invoca en «Maleficio» los excesos constitutivos del sujeto contemporáneo, se reapropia de la supuración de los procesos coloniales de sujeción y canaliza la violencia fundacional caribeña, reclamando el desarraigo del sujeto colonizado y dando salida ritual al «maleficio» antillano.

Les études d'art et de performance, parmi d'autres mouvements contemporains, ont non seulement positionné le corps comme une cartographie symbolique, mais ont également mis en évidence la nature paradoxale de la peau, sa condition de réalité périphérique, à mi-chemin entre le physique et le psychique, le psychique, l'organique et l'inorganique. Et c'est précisément à travers cette liminalité qu'une approche épidermique permet d'établir d'autres espaces de transfert, de représentation et d'agencement dans le contexte archipélagique caribéen. La peau comme espace périphérique de reconnaissance force un décentrement, une dislocation, une disjonction qui laisse entrevoir dans les produits culturels une autre totalité - symbiotique, turbulente, fractale - qui se dérobe et déborde (par le biais du poétique) les efforts de recodage postcolonial et de territorialisation. En ce sens, Marta María Pérez Bravo invoque dans "Maleficio" les excès constitutifs du sujet contemporain, se réapproprie les processus coloniaux de sujétion et canalise la violence caribéenne fondatrice, exigeant le déracinement du sujet colonisé et donnant un débouché rituel au «maléfice» antillais.

\section{ÍNDICE}

Mots-clés: liminalité, réalités archipélagiques, identités caribéennes, chaos-monde, poétique de l'épiderme.

Palabras claves: liminalidad, realidades archipelágicas, identidades caribeñas, chaos-monde, poética de lo epidérmico.

\section{AUTOR}

\section{CECILIA GONZÁLEZ GODINO}

University of Pennsylvania

Department of Romance Languages - Hispanic Studies

ceciliag@sas.upenn.edu 